\title{
XLIV. On the opposition of the Minor Planets
}

\section{Stephen Groombridge Esq. F.R.S.}

To cite this article: Stephen Groombridge Esq. F.R.S. (1826) XLIV. On the opposition of the Minor Planets, Philosophical Magazine Series 1, 67:336, 277-279, DOI: 10.1080/14786442608674057

To link to this article: http://dx.doi.org/10.1080/14786442608674057

曲 Published online: 10 Aug 2009.

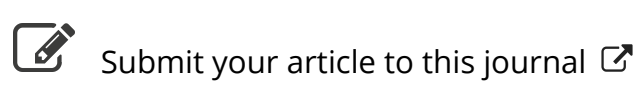

LII Article views: 3

Q View related articles $\sqsubset$ 
dried specimen; in the recent state, the knotted appearance is not distinguishable: he has also drawn it with the palms turned nearly to the earth, instead of placing them with the thumbs to the ground and the palms presenting backwards. In the recent English translation of Baron Cuvier's Règne Animal, Desmarest's figure is copied, but is rendered vastly more incorrect and unnatural than it is in the original.

Note.-In my Note on the genus Condylura recently published, it is stated that the Scalops has the integuments continued over the cartilaginous tube leading to the internal ear. I lately had an opportunity of examining several fine specimens, and have found the very small meatus auditorius externus, which will admit a body of the size of a common pin. It is by no means easily discovered, and is situated about three-fourths of an inch behind the eye, nearly over the anterior part of the shoulder joint.

XLIV. On the Opposition of the Minor Planets. By STEPHeN Groombridge, Esq. F.R.S. \&c. \&c.

HAVING computed the apparent places of these planets about the time of their respective oppositions in preceding years, from elements which required correction in the mean epoch of longitude on the orbit; particularly in Pallas, whose mean diurnal tropical motion had been assumed too great a quantity: I have now corrected their elements from the observations made at Greenwich in the last year; and the following Ephemeris will show their apparent places at midnight for 1826.

\begin{tabular}{|c|c|c|c|c|c|}
\hline & & & & & $\begin{array}{c}\text { Dist. from } \\
\Theta=1 \\
2.563\end{array}$ \\
\hline & & & & & \\
\hline & 8th & 15 & 20 & 25635 & \\
\hline & November 1st & $10 \varepsilon$ & 23 & $166 \quad 19$ & $1 \cdot 023$ \\
\hline
\end{tabular}

Pallas will appear very faint, being so distant from the earth; but Vesta and Juno being in the lower part of their orbits, will appear as stars of 6 th and 7 th magnitude.

Blackheath, April 19, 1826.

S. Groombridge. 
278 Mr. Groombridge on the Opposition of the Minor Planets.

Ephemeris at Midnight.

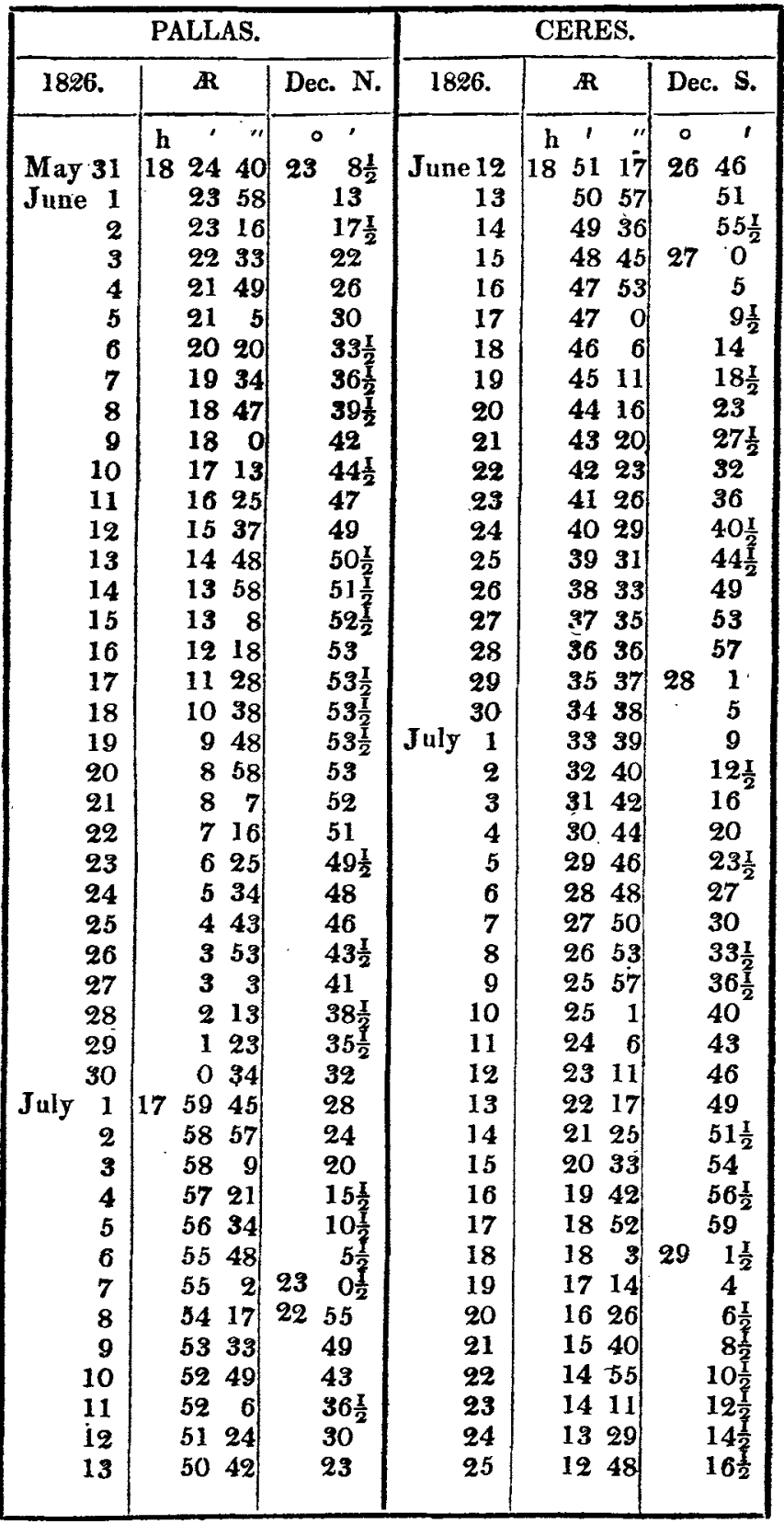


Mr. Groombridge on the Opposition of the Minor Planets. 279 Ephemeris at Midnight.

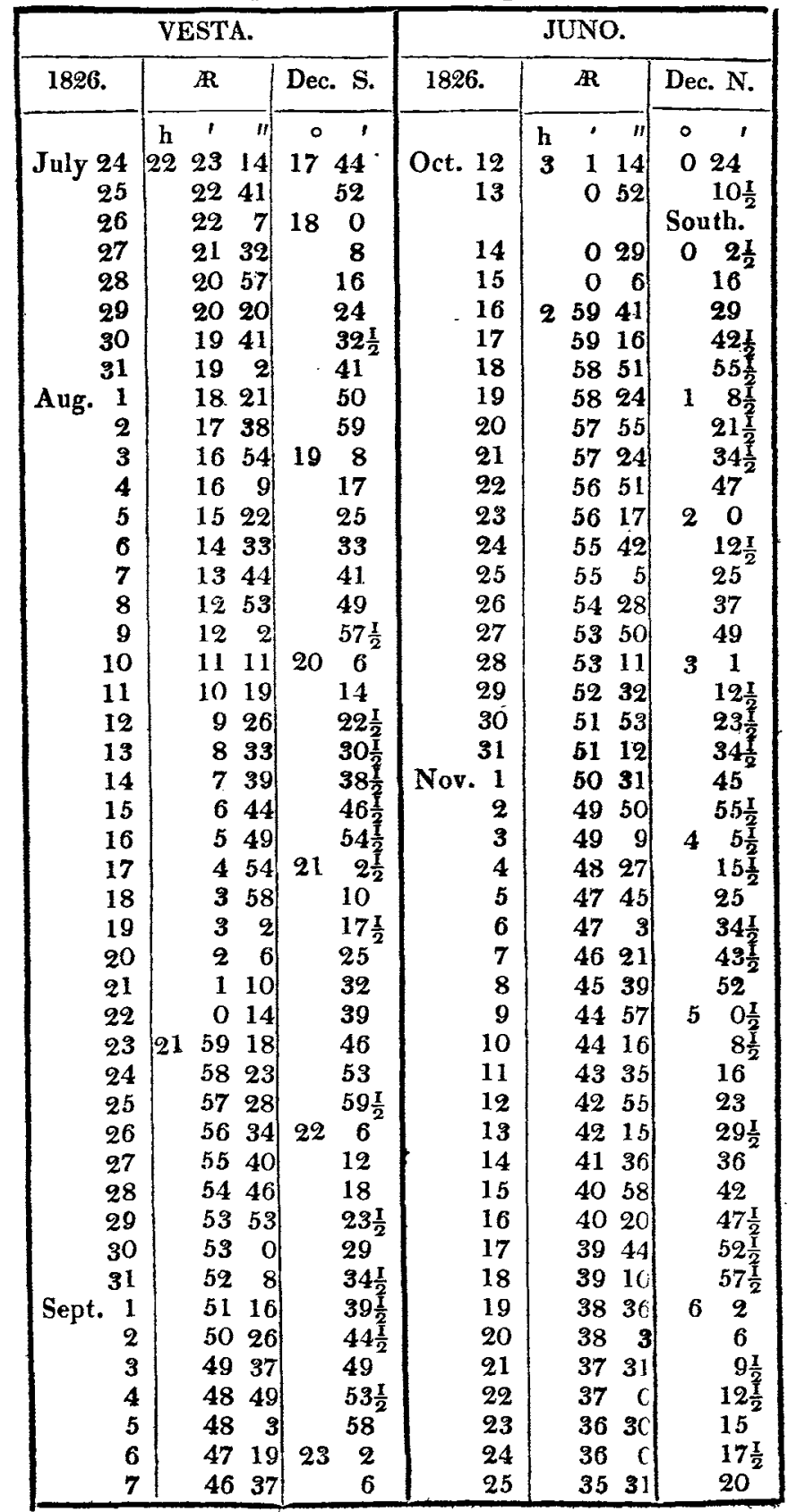

